\title{
Learning Styles Preferences Using Fuzzy Logic System
}

\author{
Wan Nurshazelin Wan Shahidan ${ }^{1 *}$, Nur Rusmawati Ishak ${ }^{2}$, Siti Nor Nadrah Muhammad ${ }^{3}$ \\ 1,2,3 Faculty of Computer and Mathematical Sciences, \\ Universiti Teknologi MARA, Perlis Branch, Arau Campus, 02600 Arau, Perlis
}

Corresponding author: * shazelin804@uitm.edu.my

Received Date: 21 December 2020

Accepted Date: 6 March 2021

Published Date: 14 March 2021

\section{HIGHLIGHTS}

- Nine variable inputs were identified to obtain the VARK learning styles output.

- Fuzzy logic system was used to determine preferred learning style based on VARK input.

- Preferred students' learning style was compared between male and female.

\begin{abstract}
Every individual has their own natural or habitual pattern of gathering and processing information in learning situations. The different environment between school and university studies will pose a significant impact on the learning style of students. The objectives of this study are to analyse the most preferred learning style among first-year diploma students in Universiti Teknologi MARA (UiTM) Perlis Branch and compare the preferred learning style among male and female students using the Fuzzy Logic System. There were nine variable inputs in determining the fuzzy logic learning styles which are reading likeness, by nature, thinking time, speaking rate, activity level, activity enjoyment, visual distraction, auditory distraction and using instruction to obtain the VARK (visual, auditory, read/write, kinaesthetic) learning styles output. The results showed that $32 \%$ of the students prefers visual learning styles based on the VARK questionnaire while for the fuzzy inferences system, $40 \%$ of the students prefer visual learning style. Additionally, $45 \%$ of male students preferred visual learning styles followed by reading/writing and kinaesthetic learning styles of 20\%. Among female students, 34\% of them also showed preferred visual learning styles, followed by reading/writing learning styles. It is concluded that the vast majority of UiTM Perlis Branch students prefers visual learning styles in their studies.
\end{abstract}

Keywords: Learning Styles, VARK, Fuzzy Logic, Fuzzy Inference System, Gender

\section{INTRODUCTION}

The different environment between school and university studies will have an impact on the learning style of students. The learning environment has changed in order to become more interconnected and centred on learners. The first year can be challenging for some students because they have to adapt with the environment and different learning styles at the university level, which differs greatly from their school years. According to Singh, Govila and Rani (2015), learning styles are mental, emotional and psychological influences that serve as relatively stable markers of how the learner feels and communicates with as well as reacts to the learning environment. A study by 
Shuib, Zavareh and Abdullah (2014) states that VARK - short for Visual, Auditory, Read/Write and Kinaesthetic - learning styles are preferable to other learning styles such as Honey and Mumford learning styles, Gardner Multiple Intelligence, Kolb learning styles and so on. Visual students, also known as a graphic learner, can retain information when confronted with images, charts, graphs and displays to name a few. Auditory learners prefer to hear spoken information and they learn best from lectures, group discussions and even using mobile phones and emails. Auditory learners generally retain the best way to speak out loud when communicating with others. The read/write style prefers written and word details. Therefore, PowerPoint slides, written instructions and lists are preferred for these types of students. Kinaesthetic learning style is a perceptual preference related to the use of experience and practice. Examples of kinaesthetic include demonstrations, stimulation, videos, and movies of 'real' material, as well as case studies and practical applications.

In particular, male and female students have different ways of thinking and learning styles that they adapt to their studies. Previous studies applied other methods to predict learning style among group of gender. In a previous study by Peyman et al. (2014), the data in that research on learning styles among the first-year medical students were analysed by using SPSS software and ChiSquare Test and the data was collected using VARK (visual, auditory, read/write, kinaesthetic) questionnaire. The result in that study showed that both male and female students preferred the Auditory learning style. Geetha and Praveena (2017) applied Correlation analysis to determine the relationship between learning style and interest in biological sciences among secondary school students. They found that there is a significant difference in the learning styles between male and female students. Besides that, by using the Fleming VARK learning styles, the findings of these studies showed that the most preferred learning styles among secondary school students are kinaesthetic learning styles. Alkooheji and Al-Hattami (2018) used a one-way between group Multivariate analysis of variance to investigate the gender difference in learning styles. The result showed that there was a significant difference between male and female students on the combined dependent variables (visual, auditory, read/write, kinaesthetic).

The fuzzy system involves an application that relates to human decision-making and provides specific solutions from approximate information (Moktar et al, 2018). Research from Almohammadi and Hagras (2013) proposed fuzzy logic system to predict learning style. The proposed system focuses on the characteristics of the learner and needs to generate a fuzzy template used to improve the knowledge of the learner. The system has been able to learn the skills required by the student and has built an effective structured learning environment based on the expectations of the learner. Alien \& Shaout (2017) stated in their research that a fuzzy inference system for predicting preferred learner style (a group of male and female students) was proposed based on the features used in the VARK questionnaire. The outcome showed that $48 \%$ of the test cases were classified in the same classification as the VARK system for learning styles by the proposed fuzzy inference system. As a result, this research inspired the use of the Fuzzy Logic System to identify the most preferred learning styles among male and female first-year diploma students in order to see changes in secondary school learning styles. 


\section{METHODOLOGY}

The population in this study are first year diploma students from six faculties in UiTM Perlis Branch for the semester of September 2019 to January 2020. Online questionnaire was used to collect data from the students by using a quota sampling method. A total of 100 first year diploma students answered the questionnaire but only 88 respondents were used for analysis. There were nine variable inputs in determining the fuzzy logic learning styles which are reading likeness, by nature, thinking time, speaking rate, activity level, activity enjoyment, visual distraction, auditory distraction and using instruction. All the variables input in this study are based on the previous study by Alian and Shaout (2017). In this study, every variable input determines different learning styles output, and there are some students who produced more than one output i.e. learning styles. For the Visual learning styles output; the reading likeness, visual distraction and auditory thinking time are used whereas for the auditory learning styles output, the methods used are the auditory distraction, by nature, thinking time, speaking rate and activity level. For Read/Write output; thinking time, using instruction and read likeness are used. Lastly, thinking time, by nature, speaking rate, activity level and activity enjoyment are used for Kinaesthetic output.

There are three steps used in this study, which are fuzzification of input and output variables, evaluation of fuzzy inference and defuzzification using MATLAB software as shown in Figure 1.

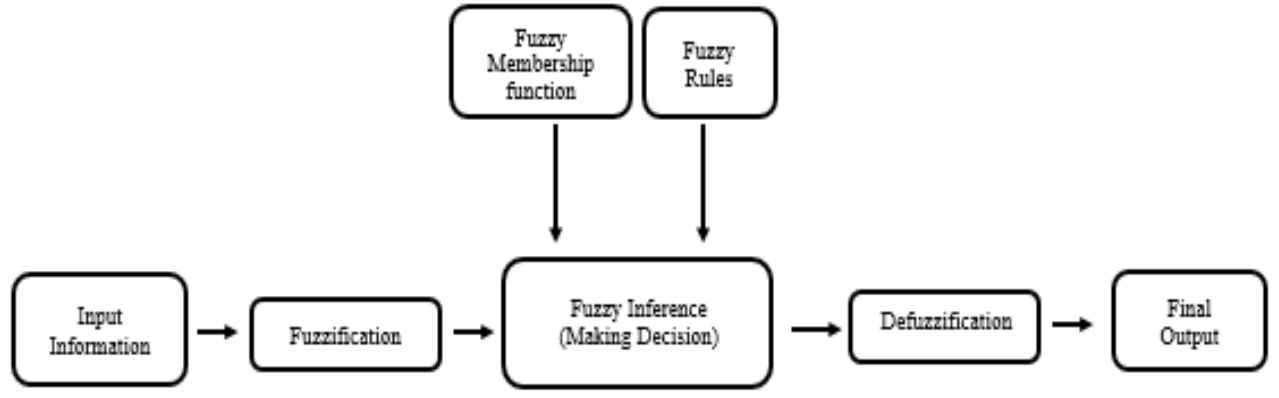

Figure 1: System of Fuzzy Logic

\section{Fuzzification}

Fuzzification is the first step in the fuzzy logic system. In this step, the linguistic variables such as 'High', 'Moderate', 'Low', 'Fast', 'Moderate' and 'Slow' will be used to obtain the result of the learning styles. These linguistic variables will be applied to represent the input and output variables such as reading likeness, thinking time, speaking rate, activity level, activity enjoyment, by nature and VARK. The membership function for the variables is calculated based on triangular and trapezoidal functions.

Table 1 shows the input and output variable with their linguistic terms. The linguistic term was provided from the previous study by (Alian \& Shaout, 2017). Figure 2 below shows the structure of the fuzzy inference system by using Mamdani. Table 2 shows the fuzzy numbers, ranges and membership functions for each input variable. 
Table 1: Input and Output Variables and Their Linguistic Terms

\begin{tabular}{|c|c|c|c|}
\hline Function & Variables & Label & Linguistic Term \\
\hline \multirow{9}{*}{$\begin{array}{c}\text { Input } \\
\text { (Learning } \\
\text { Features) }\end{array}$} & By Nature & ByNature & \{Outgoing, Quiet \\
\hline & Read Likeness & ReadLikeness & $\{$ Low, Moderate, High $\}$ \\
\hline & Thinking Time & ThinkingTime & $\{$ Fast, Moderate, Slow $\}$ \\
\hline & Speaking Rate & SpeakingRate & $\{$ Slow, Medium, Fast $\}$ \\
\hline & Activity Level & ActivityLevel & \{Mild, Moderate, Strenuous \\
\hline & $\begin{array}{c}\text { Activity } \\
\text { Enjoyment }\end{array}$ & ActivityEnjoyment & $\{$ Worse, NoDiferrence, Better $\}$ \\
\hline & $\begin{array}{c}\text { Visual } \\
\text { Distraction }\end{array}$ & VDistraction & $\{$ Low, Moderate, High $\}$ \\
\hline & $\begin{array}{c}\text { Auditory } \\
\text { Distraction }\end{array}$ & ADistraction & $\{$ Low, Moderate, High $\}$ \\
\hline & $\begin{array}{c}\text { Using } \\
\text { Instruction }\end{array}$ & UsingIntruction & $\{$ NoInstruction, VerbalIntruction $\}$ \\
\hline \multirow{4}{*}{$\begin{array}{c}\text { Output } \\
\text { (Learning } \\
\text { Styles) }\end{array}$} & Visual & VLearningStyle & $\{$ Mild, Strong, High $\}$ \\
\hline & Auditory & ALearningStyle & $\{$ Mild, Strong, High $\}$ \\
\hline & Kinaesthetic & KLearningStyle & $\{$ Mild, Strong, High $\}$ \\
\hline & Read/write & RLearningStyle & $\{$ Mild, Strong, High $\}$ \\
\hline
\end{tabular}

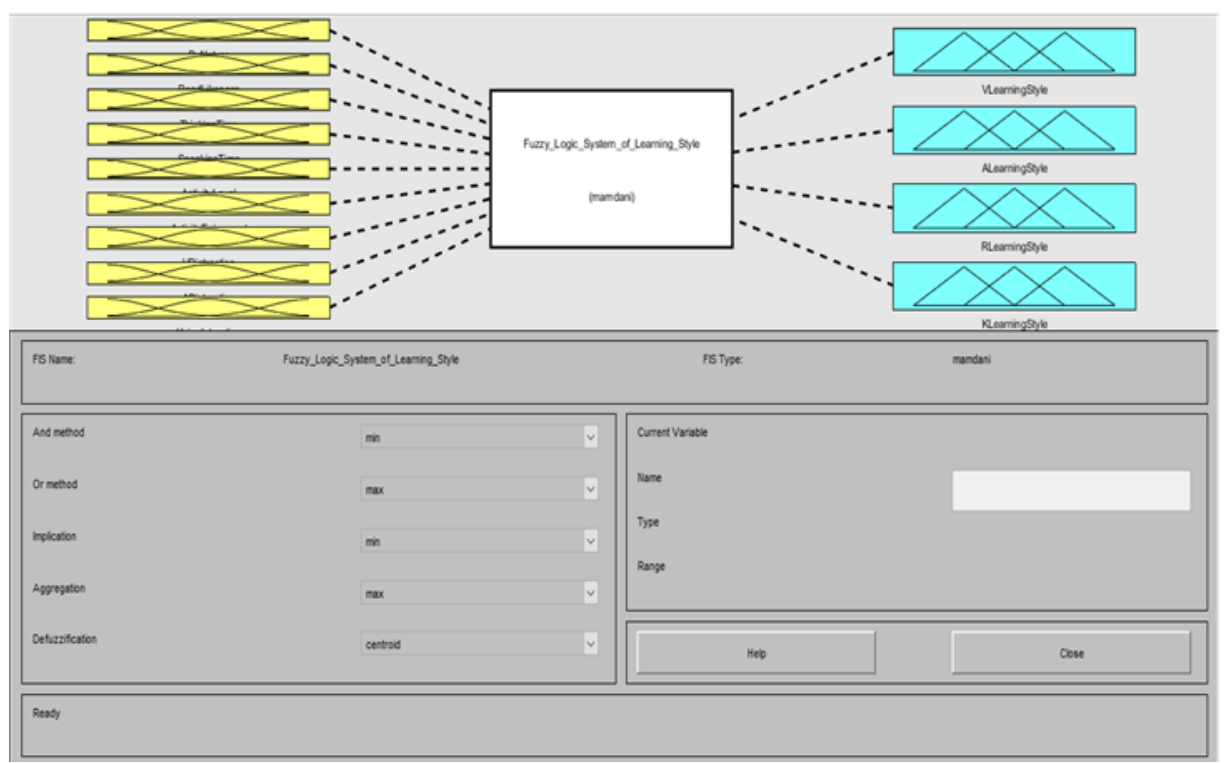

Figure 2: Fuzzy Inference System Editor 
Table 2: Fuzzy Numbers, Ranges and Membership Function for Each Input

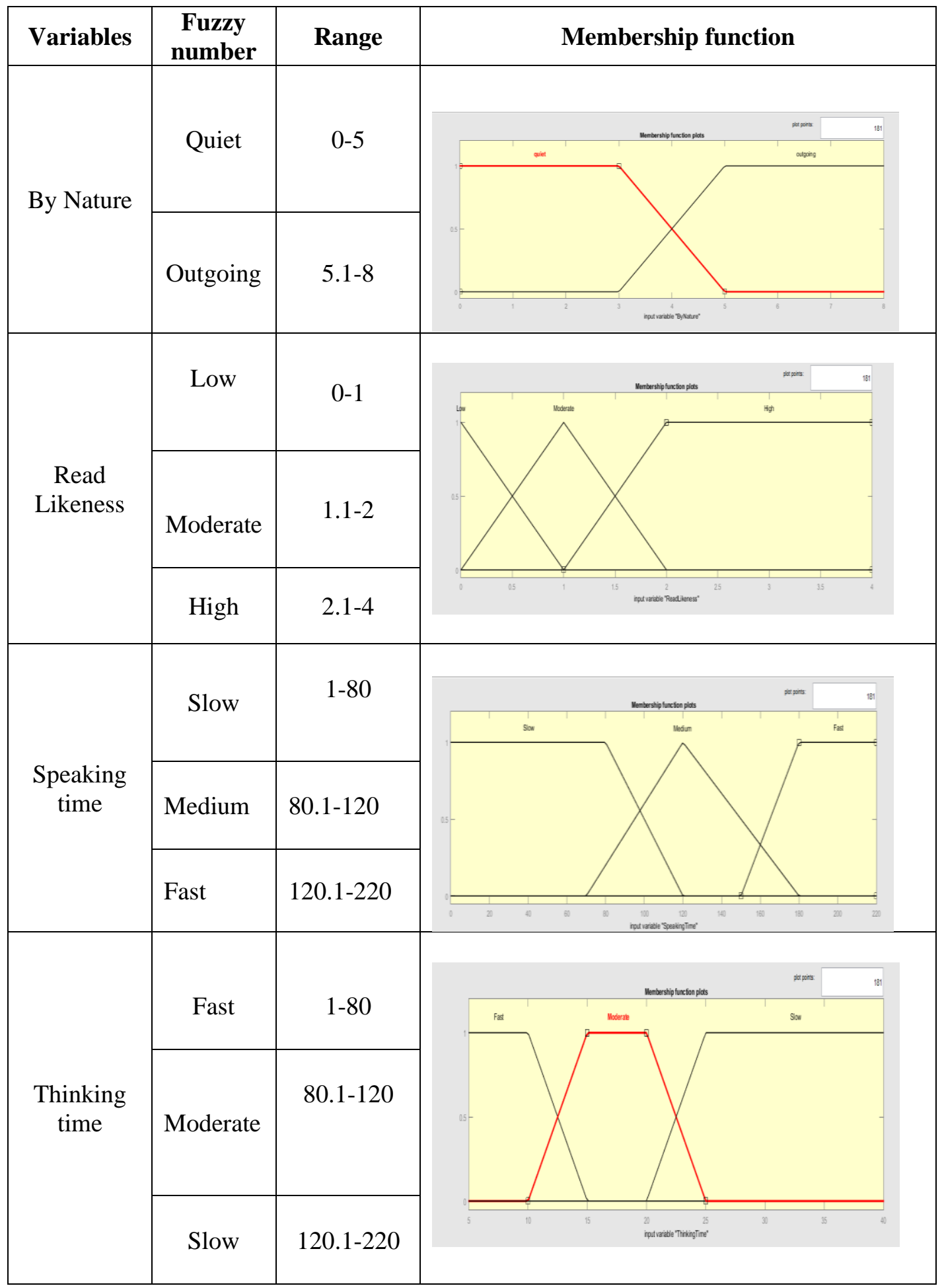




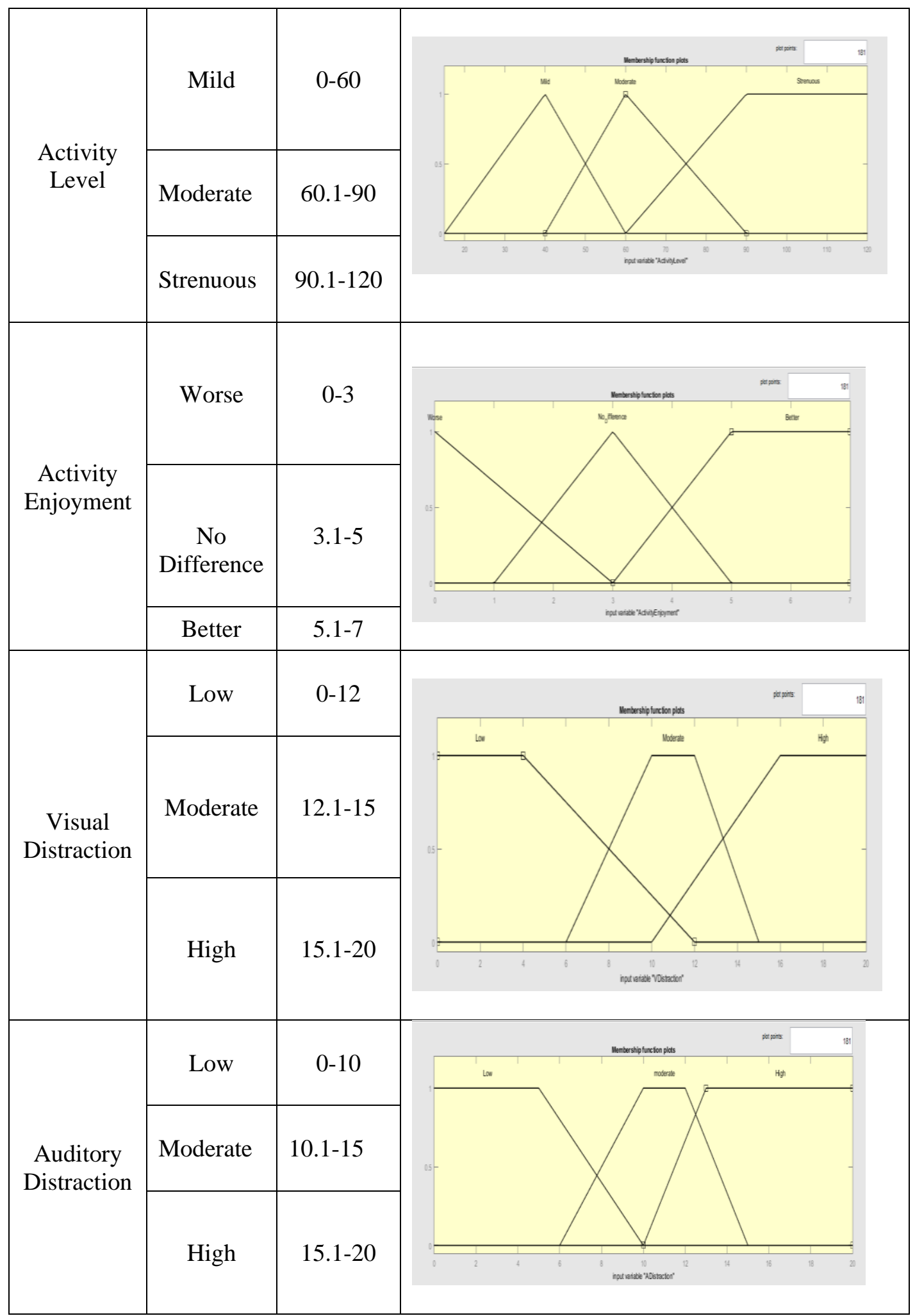




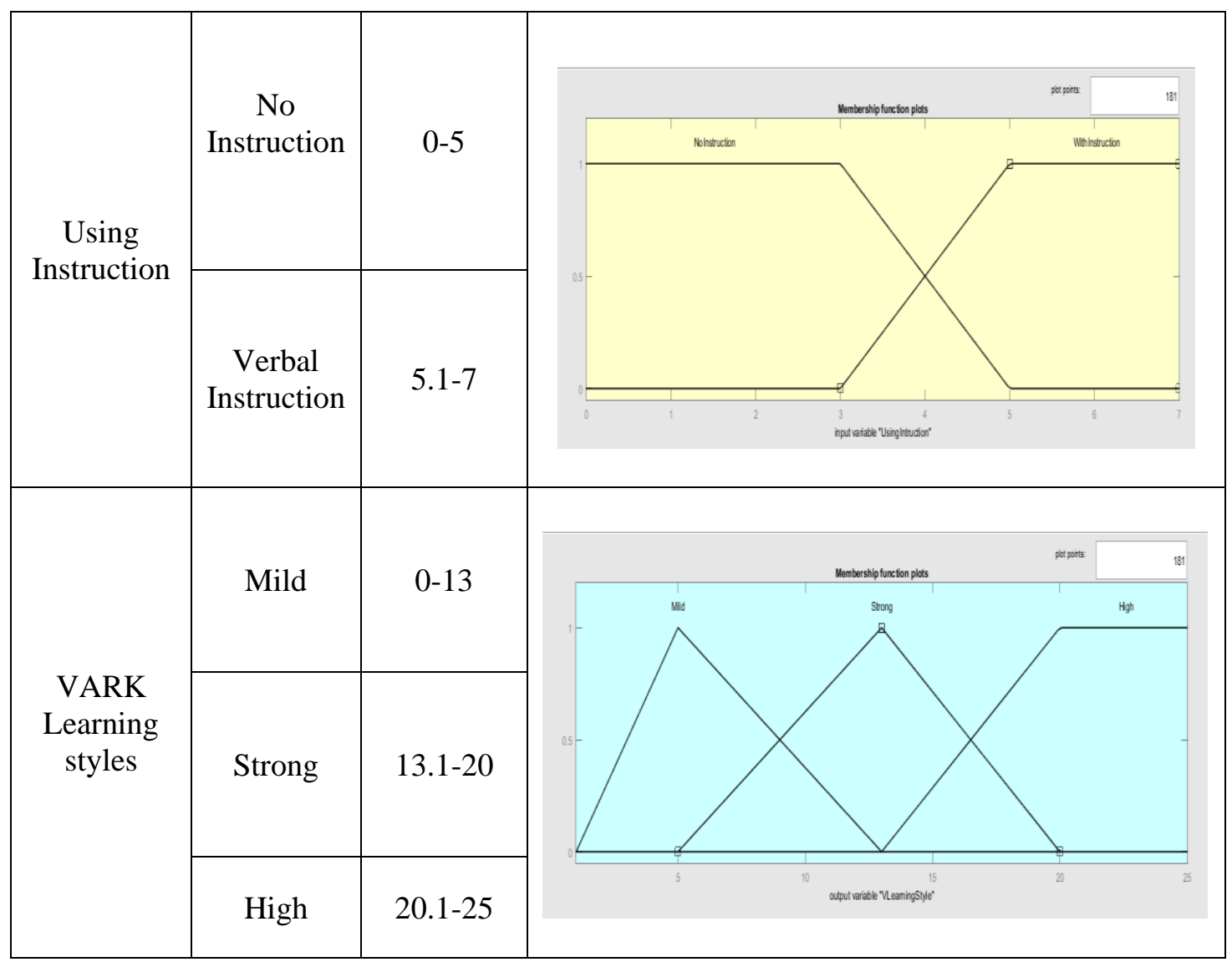

\section{Evaluation of Fuzzy Inference}

The input variables and output variables of the membership functions were applied in the Fuzzy Inference for the evaluation process. The output was generated by using IF-THEN rule with condition: "If $p$ is $A$ then $q$ is $B$ ", where $A$ and $B$ are the linguistic values to formulate the conditional statement. This rule is a simplified representation of the behaviour of a system that contains a condition and conclusion in order to help the user understand easily. The output membership function for each rule was determined based on Mamdani modelling. For Visual output there are 81 best rules generated, 162 best rules generated for Auditory output, 18 best rules produced for Read/Write output and there are 162 best rules for Kinaesthetic output. The following is part of the list of rules (example 10 rules) that was generated. The rules are then keyed in MATLAB software.

1. If (ReadLikeness is low) and (ThinkingTime is fast) and (SpeakingRate is slow) and (VDistraction is low) then (VisualLearningStyle is mild)

2. If (ReadLikeness is low) and (ThinkingTime is fast) and (SpeakingRate is slow) and (VDistraction is low) then (VisualLearningStyle is strong) 
3. If (ReadLikeness is low) and (ThinkingTime is fast) and (SpeakingRate is slow) and (VDistraction is low) then (VisualLearningStyle is high)

4. If (ReadLikeness is moderate) and (ThinkingTime is fast) and (SpeakingRate is slow) and (VDistraction is low) then (VisualLearningStyle is mild)

5. If (ReadLikeness is moderate) and (ThinkingTime is fast) and (SpeakingRate is slow) and (VDistraction is low) then (VisualLearningStyle is strong)

6. If (ReadLikeness is moderate) and (ThinkingTime is fast) and (SpeakingRate is slow) and (VDistraction is low) then (VisualLearningStyle is high)

7. If (ReadLikeness is high) and (ThinkingTime is fast) and (SpeakingRate is slow) and (VDistraction is low) then (VisualLearningStyle is mild)

8. If (ReadLikeness is high) and (ThinkingTime is fast) and (SpeakingRate is slow) and (VDistraction is low) then (VisualLearningStyle is strong)

9. If (ReadLikeness is high) and (ThinkingTime is fast) and (SpeakingRate is slow) and (VDistraction is low) then (VisualLearningStyle is high)

10. If (ReadLikeness is low) and (ThinkingTime is moderate) and (SpeakingRate is slow) and (VDistraction is low) then (VisualLearningStyle is mild)

\section{Defuzzification}

The last step in fuzzy logic systems is defuzzification which is the process to convert the value of the fuzzy membership into a single number or numerical values. Besides that, defuzzification is completed based on the membership function of the output variables. The most common in defuzzification is the centroid method which is the method used to convert the linguistic terms to numerical values. Centroid Method is the centre of gravity of all defuzzification methods and is considered the most appropriate and physically attractive.

The formula for the centroid method in defuzzification is as such:

$$
\begin{aligned}
& X^{*}=\frac{\int \mu_{c}(x) \cdot x d z}{\int \mu_{c}(x) d z} \\
& \text { where, } \\
& X^{*}=\text { Defuzzied output } \\
& \int=\text { Denoted to an algebraic integration } \\
& \mu_{c}(x)=\text { Aggregated membership function } \\
& x=\text { output variables }
\end{aligned}
$$

\section{FINDINGS AND DISCUSSIONS}

Table 3 shows the output for both the VARK and the fuzzy inference system which was obtained from the MATLAB software. The results show that $29.5 \%$ of the students have more than one preferred learning styles and only eight students out of the total 88 (shown with * in Table 3 ) offer similarity learning style with fuzzy inference system. Majority students did not give similarity VARK learning style with preferred learning style predicted by fuzzy logic system. These results also support the research conducted by Allan \& Shaout (2017). 
Table 3: The Output of the Fuzzy Inference System and the VARK Questionnaire

\begin{tabular}{|c|c|c|c|c|c|c|c|c|c|c|}
\hline \multirow{2}{*}{ Respondent } & \multicolumn{4}{|c|}{ Fuzzy Inference System } & \multirow{2}{*}{$\begin{array}{c}\text { Learner } \\
\text { Style }\end{array}$} & \multicolumn{4}{|c|}{ VARK Questionnaire } & \multirow{2}{*}{$\begin{array}{c}\text { Learne } \\
\text { Style }\end{array}$} \\
\hline & $\mathbf{V}$ & $\mathbf{A}$ & $\mathbf{R}$ & $\mathbf{K}$ & & $\mathbf{V}$ & $\mathbf{A}$ & $\mathbf{R}$ & $\mathbf{K}$ & \\
\hline 1 & 12.5 & 12.5 & 12.5 & 12.5 & VARK & 10 & 25 & 15 & 15 & A \\
\hline 2 & 13.8 & 12.5 & 12.5 & 12.8 & $\mathrm{~V}$ & 15 & 18 & 13 & 16 & A \\
\hline 3 & 12.5 & 12.5 & 12.5 & 12.5 & VARK & 18 & 22 & 8 & 13 & A \\
\hline 4 & 12.5 & 13.6 & 13.2 & 14 & $\mathrm{~K}$ & 16 & 18 & 16 & 17 & $\mathrm{~A}$ \\
\hline 5 & 13.3 & 13 & 13 & 12.5 & $\mathrm{~V}$ & 15 & 20 & 11 & 22 & $\mathrm{~K}$ \\
\hline 6 & 12.5 & 13.1 & 12.5 & 12.5 & $\mathrm{~A}$ & 23 & 17 & 17 & 18 & $\mathrm{~V}$ \\
\hline 7 & 13.8 & 13.5 & 13.2 & 13.2 & $\mathrm{~V}$ & 19 & 21 & 17 & 15 & A \\
\hline 8 & 13.5 & 12.5 & 13 & 12.5 & $\mathrm{~V}$ & 19 & 20 & 20 & 21 & $\mathrm{AR}$ \\
\hline $9 *$ & 12.9 & 13 & 12.5 & 12.5 & A & 12 & 20 & 7 & 15 & A \\
\hline 10 & 12.5 & \begin{tabular}{|l|}
12.8 \\
\end{tabular} & 12.5 & 12.5 & A & 17 & 16 & 12 & 18 & $\mathrm{~K}$ \\
\hline 11 & 12.5 & 12.5 & 13.2 & 12.5 & $\mathrm{R}$ & 18 & 14 & 12 & 19 & $\mathrm{~K}$ \\
\hline 12 & 13.5 & 13.5 & 13.2 & 13.5 & VAK & 15 & 25 & 13 & 23 & $\mathrm{~A}$ \\
\hline 13 & 13.8 & \begin{tabular}{|l}
13.2 \\
\end{tabular} & 13.2 & 13.2 & $\mathrm{~V}$ & 14 & 23 & 17 & 11 & A \\
\hline 14 & 12.9 & 12.5 & 13.2 & 12.5 & $\mathrm{R}$ & 20 & 14 & 17 & 20 & VK \\
\hline 15 & 13.5 & 12.5 & 12.5 & 12.8 & $\mathrm{~V}$ & 16 & 18 & 18 & 17 & AR \\
\hline 16 & 13.2 & \begin{tabular}{|l|}
13.1 \\
\end{tabular} & 12.5 & 13.5 & $\mathrm{~K}$ & 18 & 13 & 15 & 14 & $\mathrm{~V}$ \\
\hline 17 & 12.9 & 12.5 & 13 & 12.5 & $\mathrm{R}$ & 17 & 15 & 14 & 15 & $\mathrm{~V}$ \\
\hline 18 & 13.2 & 12.5 & 13 & 12.5 & $\mathrm{~V}$ & 14 & 16 & 12 & 18 & $\mathrm{~K}$ \\
\hline 19 & 13.3 & 12.9 & 13.2 & 12.5 & $\mathrm{AR}$ & 12 & 15 & 17 & 16 & $\mathrm{R}$ \\
\hline 20 & 12.9 & \begin{tabular}{|l|}
13.2 \\
\end{tabular} & 12.5 & 12.5 & $\mathrm{~A}$ & 15 & 17 & 21 & 15 & $\mathrm{R}$ \\
\hline 22 & 13.5 & 12.5 & 13 & 12.5 & $\mathrm{~V}$ & 13 & 13 & 16 & 22 & $\mathrm{~K}$ \\
\hline 23 & 12.5 & 12.5 & 12.5 & 12.5 & VARK & 12 & 16 & 20 & 18 & $\mathrm{R}$ \\
\hline 24 & 12.5 & 12.5 & 13.2 & 12.5 & $\mathrm{R}$ & 18 & 17 & 10 & 18 & VK \\
\hline 25 & 12.9 & 12.5 & 13.2 & 12.5 & $\mathrm{R}$ & 19 & 13 & 12 & 14 & $\mathrm{~V}$ \\
\hline 26 & 13.5 & 14 & 12.5 & 12.5 & A & 16 & 15 & 15 & 15 & $\mathrm{~V}$ \\
\hline 27 & 13.3 & \begin{tabular}{|l|}
13.2 \\
\end{tabular} & 12.5 & 12.5 & VA & 16 & 17 & 15 & 16 & $\mathrm{~A}$ \\
\hline 28 & 12.9 & \begin{tabular}{|l|}
13.2 \\
\end{tabular} & 12.5 & 12.5 & $\mathrm{~A}$ & 25 & 15 & 17 & 20 & $\mathrm{~V}$ \\
\hline 29 & 13.2 & \begin{tabular}{|l|}
13.3 \\
\end{tabular} & 12.5 & 12.5 & VA & 15 & 18 & 18 & 21 & $\mathrm{~K}$ \\
\hline 30 & 12.9 & 12.5 & 13.2 & 12.5 & $\mathrm{R}$ & 16 & 15 & 14 & 15 & $\mathrm{~V}$ \\
\hline 31 & 13.5 & \begin{tabular}{|l|}
12.8 \\
\end{tabular} & 12.5 & 12.5 & $\mathrm{~V}$ & 17 & 19 & 16 & 19 & $\mathrm{AK}$ \\
\hline 32 & 12.9 & 13.5 & 12.5 & 12.5 & A & 16 & 16 & 20 & 18 & $\mathrm{R}$ \\
\hline 33 & 12.5 & 12.5 & 12.5 & 12.5 & VARK & 17 & 20 & 15 & 21 & $\mathrm{~K}$ \\
\hline 34 & 12.5 & 12.5 & 12.5 & 12.5 & VARK & 18 & 14 & 17 & 18 & VK \\
\hline $35^{*}$ & 12.5 & 12.5 & 12.5 & 13.2 & $\mathrm{~K}$ & 18 & 21 & 15 & 19 & $\mathrm{~K}$ \\
\hline 36 & 13.2 & 12.5 & 13.2 & 13 & VR & 17 & 16 & 18 & 18 & $\mathrm{RK}$ \\
\hline $37 *$ & 12.9 & 12.5 & 13.2 & 13.2 & RK & 17 & 16 & 18 & 18 & $\mathrm{RK}$ \\
\hline 38 & 12.9 & \begin{tabular}{|l|}
12.5 \\
\end{tabular} & 13.2 & 12.5 & $\mathrm{R}$ & 17 & 12 & 8 & 11 & $\mathrm{~V}$ \\
\hline 39 & 12.9 & 12.5 & 13.2 & 12.5 & $\mathrm{R}$ & 16 & 13 & 10 & 16 & VK \\
\hline 40 & 13.2 & 12.5 & 12.5 & 13.1 & VK & 15 & 19 & 16 & 20 & $\mathrm{~K}$ \\
\hline 41 & 12.5 & 12.5 & 12.5 & 12.5 & VARK & 20 & 18 & 14 & 14 & $\mathrm{~V}$ \\
\hline
\end{tabular}




\begin{tabular}{|c|c|c|c|c|c|c|c|c|c|c|}
\hline 42 & 12.5 & 13.2 & 12.5 & 12.5 & A & 20 & 18 & 15 & 17 & $\mathrm{~V}$ \\
\hline 43 & 12.5 & 13.5 & 12.5 & 12.5 & A & 20 & 17 & 16 & 17 & $\mathrm{~V}$ \\
\hline 44 & 13.8 & 12.5 & 12.5 & 12.8 & $\mathrm{~V}$ & 15 & 18 & 13 & 16 & A \\
\hline 45 & 12.6 & 12.5 & 12.5 & 6.17 & VAR & 16 & 19 & 18 & 19 & $\mathrm{AK}$ \\
\hline 46 & 13.5 & 13.1 & 12.5 & 12.5 & $\mathrm{~V}$ & 12 & 15 & 17 & 16 & $\mathrm{R}$ \\
\hline 47 & 13 & 12.5 & 13.2 & 12.5 & $\mathrm{R}$ & 16 & 18 & 16 & 17 & $\mathrm{~A}$ \\
\hline 48 & 13.8 & 13.2 & 13 & 13.2 & $\mathrm{~V}$ & 15 & 20 & 11 & 22 & $\mathrm{~K}$ \\
\hline $49 *$ & 13.2 & 13.3 & 12.5 & 12.5 & VA & 23 & 17 & 17 & 18 & VA \\
\hline 50 & 12.5 & 12.5 & 12.5 & 12.5 & VARK & 17 & 19 & 16 & 15 & A \\
\hline 51 & 12.5 & 12.5 & 12.5 & 12.5 & VARK & 17 & 19 & 16 & 15 & A \\
\hline 52 & 12.5 & 13.5 & 12.5 & 13 & $\mathrm{~A}$ & 19 & 19 & 14 & 20 & VA \\
\hline 53 & 12.9 & 12.5 & 13.2 & 12.5 & $\mathrm{R}$ & 24 & 15 & 17 & 13 & $\mathrm{~V}$ \\
\hline 54 & 13.5 & 13.2 & 13.2 & 13.2 & $\mathrm{~V}$ & 17 & 18 & 15 & 16 & $\mathrm{~A}$ \\
\hline 55 & 12.9 & 12.5 & 13 & 12.5 & VR & 16 & 18 & 16 & 17 & $\mathrm{~K}$ \\
\hline $56^{*}$ & 13 & 12.5 & 12.5 & 12.8 & $\mathrm{~V}$ & 23 & 17 & 17 & 18 & $\mathrm{~V}$ \\
\hline 57 & 13.8 & 13.2 & 13.2 & 13.2 & $\mathrm{~V}$ & 18 & 20 & 17 & 19 & $\mathrm{~A}$ \\
\hline $58 *$ & 13.8 & 13.5 & 13.2 & 13.5 & $\mathrm{~V}$ & 21 & 15 & 15 & 16 & $\mathrm{~V}$ \\
\hline $59 *$ & 12.5 & 12.5 & 12.5 & 12.5 & $\mathrm{~V}$ & 21 & 17 & 15 & 15 & $\mathrm{~V}$ \\
\hline 60 & 12.5 & 13.2 & 12.5 & 13.2 & $\mathrm{~A}$ & 20 & 15 & 15 & 15 & $\mathrm{~V}$ \\
\hline 61 & 13.8 & 13.2 & 13.2 & 12.5 & $\mathrm{~V}$ & 15 & 21 & 15 & 20 & $\mathrm{~A}$ \\
\hline 62 & 12.9 & 12.5 & 13.2 & 12.5 & $\mathrm{R}$ & 15 & 20 & 15 & 25 & $\mathrm{~K}$ \\
\hline 63 & 12.9 & 12.5 & 13.2 & 12.5 & $\mathrm{R}$ & 18 & 16 & 15 & 22 & $\mathrm{~K}$ \\
\hline 64 & 13.8 & 14 & 13.2 & 12.5 & A & 20 & 15 & 10 & 23 & $\mathrm{~K}$ \\
\hline 65 & 12.5 & 12.5 & 12.5 & 12.5 & VARK & 15 & 20 & 10 & 19 & $\mathrm{~A}$ \\
\hline 66 & 13.8 & 13.5 & 13.2 & 12.5 & $\mathrm{~V}$ & 15 & 12 & 20 & 20 & RK \\
\hline 67 & 13.8 & 13.2 & 13.2 & 12.5 & $\mathrm{~V}$ & 15 & 13 & 20 & 24 & $\mathrm{~K}$ \\
\hline 68 & 12.9 & 12.5 & 13.2 & 12.5 & $\mathrm{R}$ & 18 & 18 & 14 & 25 & $\mathrm{~K}$ \\
\hline 69 & 13.5 & 12.5 & 13.2 & 12.5 & $\mathrm{~V}$ & 13 & 19 & 14 & 22 & $\mathrm{~K}$ \\
\hline 70 & 12.5 & 13.5 & 13.2 & 12.5 & A & 23 & 14 & 15 & 18 & $\mathrm{~V}$ \\
\hline 71 & 12.5 & 12.5 & 12.5 & 12.5 & VARK & 17 & 16 & 16 & 17 & VK \\
\hline 72 & 12.6 & 12.5 & 12.5 & 6 & VAR & 15 & 16 & 17 & 19 & $\mathrm{~K}$ \\
\hline 73 & 13.5 & 12.5 & 13.2 & 12.5 & $\mathrm{~V}$ & 16 & 21 & 18 & 16 & $\mathrm{~A}$ \\
\hline 74 & 13.8 & 13.5 & 13.2 & 13.2 & $\mathrm{~V}$ & 15 & 18 & 15 & 16 & $\mathrm{~A}$ \\
\hline 75 & 14 & 12.5 & 12.5 & 14 & VK & 14 & 15 & 14 & 21 & $\mathrm{~K}$ \\
\hline 76 & 12.9 & 12.5 & 13.2 & 12.5 & $\mathrm{R}$ & 17 & 18 & 15 & 14 & $\mathrm{~A}$ \\
\hline 77 & 12.5 & 13.1 & 12.5 & 13.2 & $\mathrm{AK}$ & 20 & 18 & 17 & 16 & $\mathrm{~V}$ \\
\hline 78 & 13.2 & 12.5 & 13.2 & 12.5 & VR & 19 & 14 & 17 & 16 & $\mathrm{~V}$ \\
\hline 79 & 13.5 & 12.5 & 12.5 & 13.2 & $\mathrm{~V}$ & 14 & 17 & 15 & 17 & $\mathrm{AK}$ \\
\hline 80 & 13.8 & 13.5 & 13.2 & 12.5 & $\mathrm{~V}$ & 15 & 20 & 17 & 13 & $\mathrm{~A}$ \\
\hline 81 & 14 & 13.5 & 12.5 & 12.9 & $\mathrm{~V}$ & 16 & 18 & 16 & 17 & $\mathrm{~A}$ \\
\hline 82 & 13.2 & 13.2 & 12.5 & 12.9 & VA & 15 & 16 & 16 & 16 & ARK \\
\hline 83 & 12.5 & 12.8 & 12.5 & 13.2 & $\mathrm{~K}$ & 17 & 18 & 18 & 18 & ARK \\
\hline 84 & 12.9 & 12.8 & 13 & 12.5 & $\mathrm{R}$ & 18 & 20 & 15 & 14 & $\mathrm{~A}$ \\
\hline 85 & 12.9 & 12.5 & 13 & 12.5 & $\mathrm{R}$ & 21 & 12 & 19 & 16 & $\mathrm{~V}$ \\
\hline
\end{tabular}




\begin{tabular}{|c|c|c|c|c|c|c|c|c|c|c|}
\hline 86 & 12.9 & 12.5 & 13.2 & 12.5 & $\mathrm{R}$ & 13 & 18 & 15 & 15 & $\mathrm{~A}$ \\
\hline $87^{*}$ & 12.5 & 12.8 & 12.5 & 14 & $\mathrm{~K}$ & 17 & 16 & 16 & 19 & $\mathrm{~K}$ \\
\hline 88 & 13.2 & 12.5 & 12.5 & 13.2 & $\mathrm{VK}$ & 19 & 14 & 18 & 18 & $\mathrm{~V}$ \\
\hline
\end{tabular}

Figure 3 shows the percentage of the preferred learning styles between Fuzzy Inference System (FIS) and VARK learning style. The most preferred learning style based on FIS is the Visual learning style with $40 \%$, followed by the Read/Write learning style which covers $27 \%$ of the students. On the other hand, preferred learning style shown from VARK questionnaire that $32 \%$ is Visual learning style and Auditory learning style, while the Read/Write was the least preferred learning style made up of $11 \%$. Both of the results demonstrates that most of the students prefer a visual learning styles as their main learning styles.

Figure 4 below shows the percentage of preferred learning styles among male and female students. Based on the figures, it can be seen that $45 \%$ of male students preferred visual learning styles compared to other styles. This is followed by read/write and kinaesthetic learning styles which is made up of $20 \%$. Apart from that, female students also preferred visual learning styles which is then followed by read/write learning styles comprising $34 \%$ of the total female students.

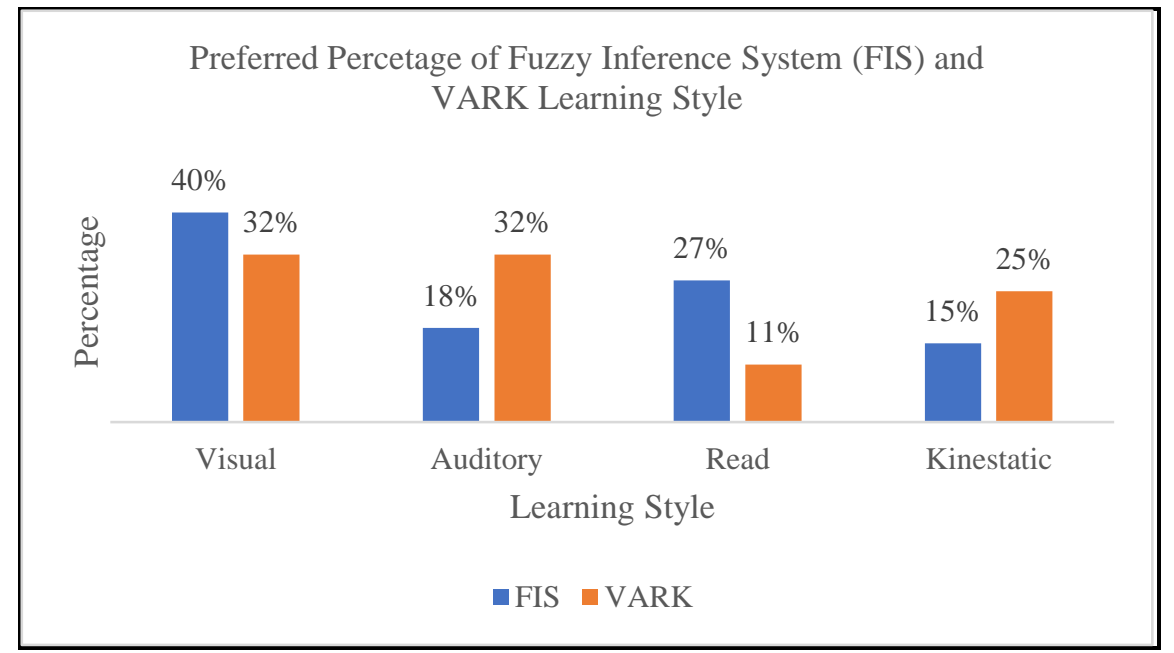

Figure 3: Preferred Percentage of Fuzzy Inference System and VARK Learning Style 


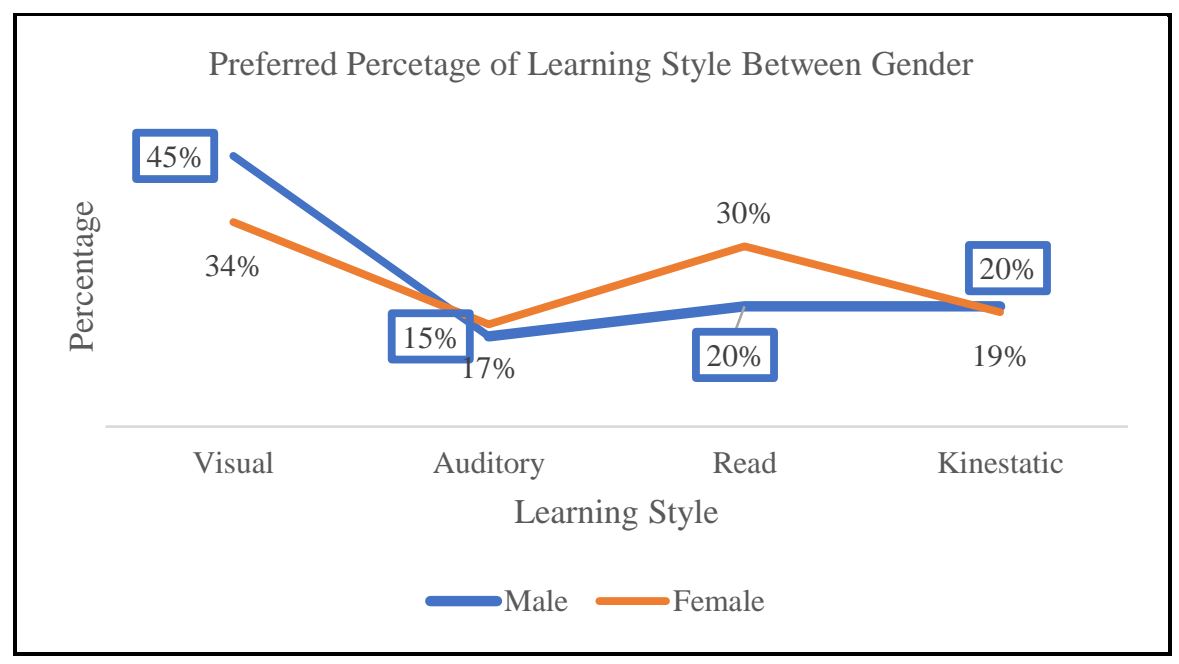

Figure 4: Percentage of Preferred Learning Styles by Male and Female Students

\section{CONCLUSION AND RECOMMENDATIONS}

Fuzzy Logic System can be used in order to determine the preferred learning styles among the first-year diploma students in Universiti Teknologi MARA (UiTM) Perlis Branch. The output obtained from the fuzzy inference system shows the similarity result with the VARK score, which proved that the Visual learning style is the most preferred learning style among students. Based on the fuzzy inference system, the result also reveals that both male and female students choose Visual learning style as their chosen method in their education. For future works, the fuzzy system should test for more respondents so as to provide a more accurate representation of the learning style among first-year diploma students. Other forms of learning styles such as Felder Silverman learning style model and sensing/intuitive or sequential/ global should be considered for further research.

\section{REFERENCES}

Alian, M., \& Shaout, A. (2017). Predicting learners' styles based on fuzzy model. Education and Information Technologies, 22(5), 2217-2234.

Almohammadi, K., \& Hagras, H. (2013). An adaptive fuzzy logic based system for improved knowledge delivery within intelligent ELearning platforms. IEEE International Conference on Fuzzy Systems, $1-8$.

Alkooheji, L., \& Al-Hattami, A. (2018). Learning Style Preferences among College Students. International Education Studies, 11(10), 50-63.

Geetha, M. C., \& Praveena, K. B. (2017). Learning styles of secondary school students and their interest in biological science. Learning, 2(5). 
Moktar, B., \& Mohd Razali, M. H. (2018). A Fuzzy Logic Approach to Measure Underweight Among Kindergarten's Kids. Journal of Computing Research and Innovation, 3(3), 36-45. Retrieved from https://crinn.conferencehunter.com/index.php/jcrinn/article/view/76

Peyman, H., Sadeghifar, J., Khajavikhan, J., Yasemi, M., Rasool, M., Yaghoubi, Y. M., ... \& Karim, H. (2014). Using VARK approach for assessing preferred learning styles of first year medical sciences students: a survey from Iran. Journal of clinical and diagnostic research: JCDR, 8(8), GC01.

Singh, L., Govil, P., \& Rani, R. (2015). Learning style preferences among secondary school students. International Journal of Recent Scientific Research, 6(5), 3924-3928.

Shuib, L., Zavareh, A. A., \& Abdullah, R. (2014). Fuzzy multi-criteria evaluation of research materials based on learning style. ARPN Journal of Engineering and Applied Sciences, 9(10), 1713-1717. (SCOPUS-Indexed). 